\title{
ATRIAL STRAIN IN ATRIAL FIBRILLATION PATIENTS: A 2D SPECKLE TRACKING ECHOCARDIOGRAPHY STUDY
}

\author{
Maria-Luiza Toplicianu ${ }^{1}$, Ioan Tiberiu Nanea ${ }^{1,2}$ \\ ${ }^{1 " C a r o l ~ D a v i l a " ~ U n i v e r s i t y ~ o f ~ M e d i c i n e ~ a n d ~ P h a r m a c y, ~ B u c h a r e s t, ~ R o m a n i a ~}$ \\ Departament of Cardiology, "Theodor Burghele" Clinical Hospital, Bucharest, Romania \\ Adresa de contact: Maria-Luiza Toplicianu, Sipotul Fântânilor Street, nr 2, 1 th District, \\ Bucharest, Romania \\ E-mail: m.luiza.toplicianu@gmail.com
}

\begin{abstract}
Objectives. In this study we tried to determine the values of the left atrial (LA) strain in patients with atrial fibrillation (AF) and set a parameter that could be a predictor of sinus rhythm (SR) maintenance.
\end{abstract}

Study population. We included 60 patients with left ventricular ejection fraction (LVEF) $\geq 50 \%$ - 33 (55\%) of them were known to have in their personal history AF (newly diagnosed, paroxysmal and persistent) and they were examined at SR. The second group was represented by 27 (45\%) patients that were examined in AF. Using two dimensional speckle tracking echocardiography (2D STE) it was quantified the strain of the 3 functions that characterize the physiology of the LA - reservoir, conduct and pump in the apical sections, mentioning that the pump was absent in patients examined in AF.

Results. The average of the reservoir (R\%) for all sections had a significantly higher value in patients with $S R(20,2 \pm 6,225 \%)$ compared to patients examined in $A F(6,505 \pm 2,66 \%)$ : $P<0.001$. With the help of the logistic regression model was observed that only systolic $L A$ strain had the highest predictive power of maintenance of SR. The cutt off value of $\geq 13,25 \%$ of the $R \%$ has a sensitivity ( $\mathrm{Se}$ ) and a specificity (Sp) of $90,9 \%$, respectively $100 \%$ for maintenance of $S R$.

Conclusions. In the present study, after analyzing all the parameters that were associated between the 2 groups, it was found that only $R \%$, as the only variable, has the highest predictor power for maintenance of SR.

\section{Rezumat}

Obiective. În acest studiu am încercat să determinăm valorile strain-ului atrial stâng la pacienţii cu fibrilaţie atriala $(A F)$ şi să stabilim un parametru care ar putea fi predictor al menţinerii ritmului sinusal (SR). 


\section{INTERNAL}

\section{Original papers}

Material şi metodă. Am inclus 60 de pacienţi cu fracţie de ejecţie a ventriculului stâng $\geq 50 \%$. Dintre aceştia, 33 (55\%) erau cunoscuţi ca având în antecedentele personale istoric de AF (nou diagnosticată, paroxistică, persistentă) și au fost examinaţi în prezenţa SR. Al doilea grup a fost reprezentat de 27 de pacienti (45\%) ce au fost examinati în AF. Utilizând ecografia 2D speckle tracking (2D STE) s-a cuantificat strain-ul celor 3 funcţii ce caracterizează fiziologia atrială stângă - rezervor, conduct și pompă în secţiunile apicale, cu menţiunea că funcţia de pompă a fost absentă la pacientii analizaţi în AF.

Rezultate. Media strain-ului de rezervor (R\%), pentru toate cele 3 secțiuni, a avut o valoare semnificativ mai mare la pacienții în SR (20,2 $26,225 \%)$ comparativ cu pacientii examinaţi în AF (6,505 22,66\%): $P<0,001$. Cu ajutorul modelului de regresie logistică, s-a observat că doar strain-ul atrial în timpul fazei de rezervor a avut cea mai mare putere de predicţie a menţinerii SR.Valoarea cut-off $\geq 13,25 \%$ a $R \%$ are o sensibilitate (Se) şi o specificitate (Sp) de 90,9\%, respectiv $100 \%$ pentru menţinerea $S R$.

Concluzii. În studiul prezent, în urma analizei tuturor parametrilor ce s-au asociat între cele 2 loturi, s-a constatat că doar strain-ul atrial de rezervor, ca singură variabilă, are cea mai mare putere de predicţie a menţinerii SR.

Cuvinte cheie: fibrilaţia atrială, strain de rezervor, predicţie, ritm sinusal.

\section{Background}

Atrial fibrillation is the most common cardiac arrhythmia, which affects $1-2 \%$ of the population, and its prevalence increases with age, from below $0,5 \%$ in patients aged $40-50$ years to $5-15 \%$ in 80 year old patients ${ }^{(1)}$. It is associated with increased mortality and morbidity that occurs primarily as a result of its complications: thromboembolism and heart failure ${ }^{(2)}$. The left atrial mechanical function has 3 phases: reservoir phase, conduct phase and pump phase; these functions can be quantified with the help of volumetric analysis, transmitral spectral Doppler, pulmonary vein flow, tissue Doppler imaging (TDI) and speckle tracking. The 2D STE ultrasound is a modern technique that allows quantitative evaluation of the parameters of myocardial longitudinal deformation: strain and strain rate $(S R)^{(3)}$. Normal values of LA strain and SR have been described in several studies. A meta-analysis from 2017 that examined the left atrial 
function with the help of 2D STE revealed that the average value of the reservoir (R\%), conduit (CDC\%) and pump (Pump\%) strain was of $39,4 \%, 23 \%$, respectively $17,4 \%$, having as reference point the QRS complex ${ }^{(10)}$. Left atrial dilation and decreased of reservoir and conduit function and the reduction or absence of the pump function are common in patients with AF and are able to predict the occurrence of adverse cardiovascular events. ${ }^{4}$

\section{Materials and method}

We analyzed through ultrasound (2D and STE) 60 patients. Of these, 33 patients (group A) were known to have a history of AF and were examined in SR, and the other 27 patients (group B) were examined in $\mathrm{AF}$ (newly diagnosed, persistent long time, permanent). In group $A$, female patients represented a $63,6 \%$, and in group $B 15$ patients were male $(55,6 \%)$ and 12 female $(44,4 \%)$, the differences not being statistically significant between the two groups : $\mathrm{P}=0.137$

The average age \pm the standard deviation (SD) was $68,39 \pm 10,877$ in group $A$ and 75 $\pm 7,85$ in group $B$, so the patients examined in SR had a significantly younger age compared to the patients examined in AF: $\mathrm{P}=0.008$

The exclusion criteria were as follows: LVEF $<50 \%$, history of myocardial infarction, history of cardiac surgery, cardiac transplant, mitral valvulopathies more than moderate, aortic valvulopathies more than moderate, cardiostimulated patients, chronic obstructive pulmonary disease, congenital cardiopathies. The informed consent of the patients and the approval by the local ethics commission for conducting the study were obtained. The standard transthoracic ultrasound was performed with a Vivid E9 ultrasound (GE Medical System, Northway), equipped with the M4S probe that was used for all examinations and defined the anatomy of the heart, valvular impairment and left ventricular function (LV). Particular attention was paid to the apical sections to avoid shortening LV or LA. The 2D images and quantification using the Doppler technique were obtained according to the guidelines implemented by the American Society of Cardiology ${ }^{5}$ and the European Association of Cardiac Imaging ${ }^{(6)}$. The telediastolic and telesystolic diameters of the LV were measured, and the LVEF was visually assessed. Diastolic function was quantified by using the PW transmitter Doppler in the apical 4 chamber view (Ap4C) , and the deceleration time of the $E$ wave (TDE) and E/A (the ratio of the maximum velocity of early diastolic filling to that of late diastolic filling) was calculated. With the help of TDI the tissue velocities from early diastole $\left(e^{\prime}\right)$ and late diastole ( $\left.a^{\prime}\right)$ were measured. The $E / E$ ' ratio was calculated for the estimation of LV telediastolic pressures (LVEDP). E' was obtained through the average between the velocities of early diastole at the level of the septal mitral ring and the lateral one. In the case of patients with AF, for the estimation of TDE and of the wave velocities of $E$ and $e^{\prime}$, the average of 5 consecutive cycles was calculated. The atrial volumes were measured by the biplane method in the Ap4c and apical 2 chamber view (Ap2C) at 3 frames of reference of the cardiac cycle (in the case of patients in SR): the frame before the $P$ wave (the left atrial volume at the atrial presystole-VpreA), the frame at the closure of the mitral valve (minimum left atrial volume - Vmin) and the frame just before the opening of the mitral valve (maximum left atrial volume - Vmax). In group B, Vmin and Vmax were determined by calculating the 


\section{INTERNAL}

\section{Original papers}

average of 5 consecutive cycles. The maximum indexed atrial volume (LAVI) was obtained through the average Vmax in the sections Ap 4C and Ap2C, a value that was indexed to the body surface (BSA). The volumes measured above were then integrated into formulas in order to define the corresponding volumetric functions.

Thus, the volumetric fractions were calculated:

- LAEI (left atrial expansion index) = Vmax-Vmin / Vmin $\times 100$

- LAEF (left atrial ejection fraction) = Vmax-Vmin/Vmax $\times 100$

- Passive LAEF (passive left atrial ejection fraction) $=$ Vmax-VpreA / Vmax $\times 100$

- Active LAEF (active left atrial ejection fraction $)=$ Vpre A-Vmin $/$ Vpre A $\times 100$

LAEI and LAEF were used for reservoir function appreciation, Passive LAEF for conduit function and Active LAEF for pump function. The volumetric functions were then correlated with the atrial strain parameters corresponding to each phase.

\section{D STE}

For STE analysis it is a conventional 2D ultrasound use, or electrocardiographic (ECG) data. Particular attention was paid to obtaining a good visualization of the myocardium and extracardiac anatomical structures. The frame rate was set between 60-80 frames / second. By manually tracing a system to the atrial endocardium, it is an automatic generation of the region of interest (ROI) that can be adjusted and divided into 6 segments for each section. The software rejected the atrial segments with poor image quality. It favors the longitudinal atrial layer analysis. We respect EACVI published in 2018, which perhaps proposed as a reference point the QRS complex. With the help of ultrasound programs, the time of closure of the aortic valve (AVC) and the opening of the mitral valve (MVO) were identified within the cardiac cycle.

For each left atrial function the global strain was calculated in Ap4C, Ap2C and apical 3 chamber view( Ap3C). An average was made for each function between the 3 apical sections (the average of the reservoir strain$\mathrm{R} \%$, the average of the conduit strain- CDC\%, the average of the pump strain-Pump\%).

For the patients examined in the RS, the following formulas were used:

- The reservoir strain was calculated by calculating the difference between the value of the strain measured at the time of the AVC (Figure 1) of the cardiac cycle and the strain at the end of the LV diastole (Figure 3) (positive value).

- The conduit strain was obtained by calculating the difference between 


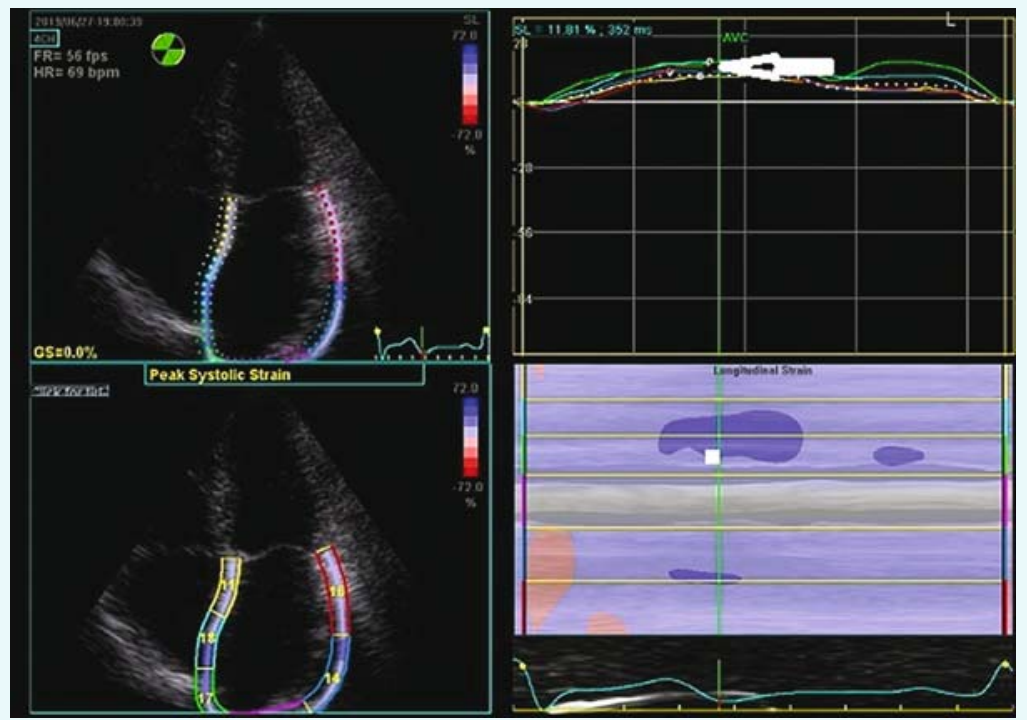

Figure 1. Two dimensional speckle tracking echocardiography. The arrow indicates the left atrial global longitudinal strain during systole (Reservoir function)

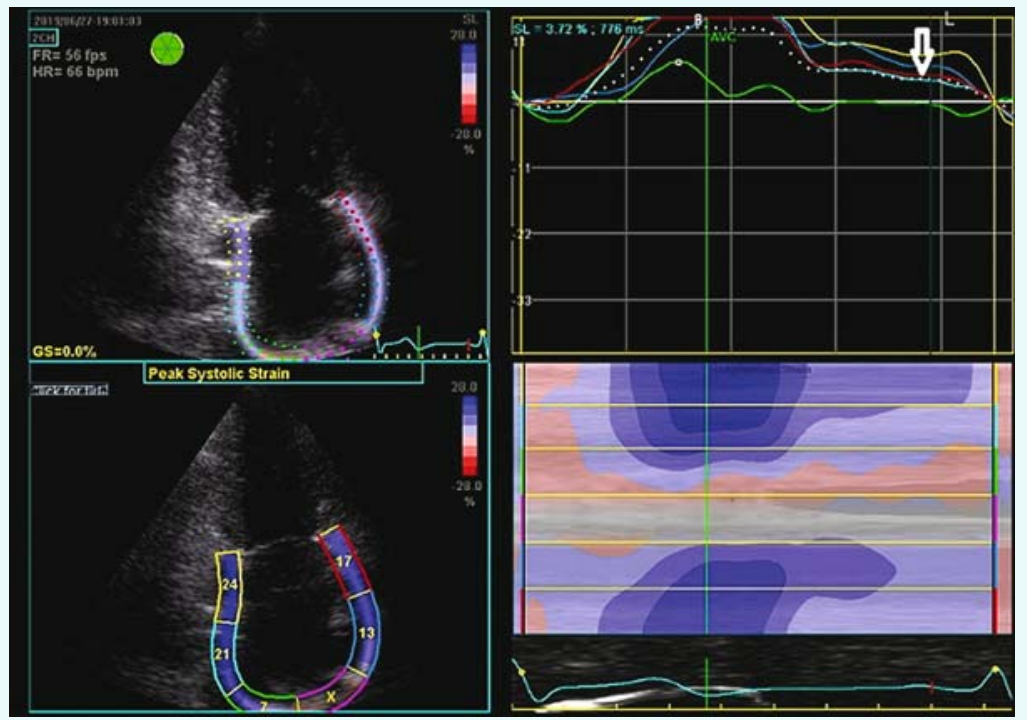

Figure 2. Two dimensional speckle tracking echocardiography. The arrow indicates the left atrial global longitudinal strain during early diastole (Conduit function)

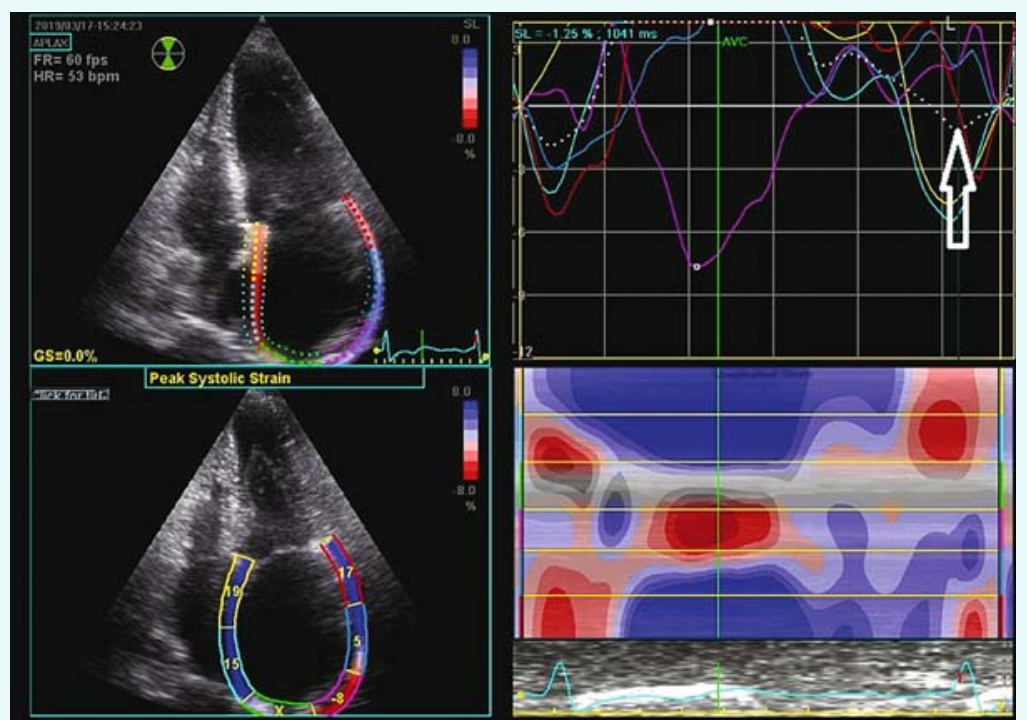

Figure 3. Two dimensional speckle tracking echocardiography. The arrow indicates the left atrial global longitudinal strain during late diastole (Pump function) 


\section{INTERNAI}

\section{Original papers}

the value of the strain at the beginning of the atrial contraction (Figure 2 ) and the value of the strain at the moment of AVC (negative value).

- The pump strain = The value of the strain in the LV telediastole - the strain at the beginning of the atrial contraction (negative value).

For patients in group $B$, the reservoir strain was defined following the identification of the maximum point of the global atrial strain at the beginning of the LV diastole- at the time of AVC (positive value); the reservoir strain had the same value with $\mathrm{R} \%$, but with minus.

The statistical analysis was performed using IBM SPSS Statistics 20 and Microsoft Office Excel/Word 2013. The quantitative variables were tested for distribution using the Shapiro-Wilk test and were expressed in the form of averages with standard deviations and the categorical variables were expressed in absolute form or percentages.

The independent quantitative variables with non-parametric distribution were tested using the Mann-Whitney $U$ test or the Kruskal Wallis $\mathrm{H}$ test, and the existing correlations were proved by using the Spearman's Tho correlation coefficient. The independent quantitative variables with parametric distribution were tested usint the Student or One-Way/Welch ANOVA test and the existing correlations were proved using the Pearson correlation coefficient. The qualitative variables were tested using Fisher's Exact Test/ Pearson Chi-Square test, after which any correlation was tested using the Pearson contingency coefficient. The Bonferroni Ztests were performed to detail the results obtained in testing the qualitative variables. The Tukey HSD/ Games-Howell/ DunnBonferroni tests were post-hoc tests performed to detail the results obtained in the testing of independent quantitative variables.

\section{Results}

In our study, the majority of the patients examined in SR had rare episodes of paroxysmal AF (45,5\%)(Figure 4), whereas in group $B$ the majority of patients were examined in permanent $A F(59,3 \%)$.

The BSA and body mass index (BMI) did not significantly vary between the two groups: $\mathrm{P}=$ 0.645 , respectively $P=0.273$; the average \pm SD of BMI in group A was $27.43 \pm 5,29 \mathrm{~kg} / \mathrm{m} 2$ and $28,28 \pm 5,89 \mathrm{~kg} / \mathrm{m} 2$ in group $B$. For BSA the average difference between groups was insignificant: 0,058 $\mathrm{m} 2$.

Regarding the echocardiographic characteristics, it was observed that the antero-posterior diameter (AP Diameter), LAVI and Vmin were significantly larger in group $B: P<0.001$. (Table 1 ) The degree of mitral regurgitation was significantly higher in patients examined in AF $(P=0.001), 73,10 \%$ 


\begin{tabular}{|c|c|c|c|}
\hline \multicolumn{4}{|c|}{$\begin{array}{l}\text { Echocardiographic characteristics parameters in SR patients } \\
\text { and in AF patients }\end{array}$} \\
\hline Parameters & $\begin{array}{c}\text { SR } \\
\text { Mean } \pm \text { SD }\end{array}$ & $\begin{array}{c}\text { AF } \\
\text { Mean } \pm \text { SD }\end{array}$ & P value \\
\hline LV- TDD (mm) & $46.52 \pm 4.16$ & $48 \pm 4.4$ & $0.186 * *$ \\
\hline LV- TSD (mm) & $27.73 \pm 3.1$ & $28.59 \pm 2.96$ & $0.278 * *$ \\
\hline LVEF (\%) & $57.58 \pm 4.86$ & $54.2 \pm 3.75$ & $0.004^{\Delta}$ \\
\hline AP Diameter (mm) & $38.78 \pm 3.88$ & $44.74 \pm 6.83$ & $<0.001 * *$ \\
\hline LAVI ( $\mathrm{ml} / \mathrm{m} 2)$ & $42.46 \pm 10.6$ & $68.26 \pm 26.3$ & $<0.001^{\Delta}$ \\
\hline Vmax Ap4C (mm) & $75.97 \pm 19.6$ & $117.5 \pm 47.3$ & $<0.001 * *$ \\
\hline Vmax Ap2C (mm) & $81.54 \pm 20$ & $\begin{array}{c}114.7(87.1- \\
148.7)\end{array}$ & $<0.001^{\Delta}$ \\
\hline VpreaA Ap4C (mm) & $57.95 \pm 21.1$ & & - \\
\hline Vpre A Ap2C(mm) & $67.04 \pm 23.2$ & & - \\
\hline Vmin Ap4C (mm) & $44.95 \pm 20.3$ & $99.24 \pm 43.6$ & $<0.001 * *$ \\
\hline Vmin Ap2C (mm) & $47.74 \pm 20.4$ & $112 \pm 53.75$ & $<0.001^{\Delta}$ \\
\hline LAEI (\%)Ap4C & $89.23 \pm 54.4$ & $23.32 \pm 18.1$ & $<0.001^{\Delta}$ \\
\hline LAEI (\%)Ap2C & $96.48 \pm 72.5$ & $18.6 \pm 19.6$ & $<0.001^{\Delta}$ \\
\hline LAEF (\%)Ap4C & $42.35 \pm 17.1$ & - & - \\
\hline LAEF (\%) Ap2C & $43.88 \pm 18.5$ & - & - \\
\hline Passive (\%) LAEF Ap4C & $26.73 \pm 15.3$ & - & - \\
\hline Passive (\%) LAEF Ap2C & $31.67 \pm 20$ & - & - \\
\hline Active (\%)LAEF Ap4C & $23.18 \pm 13$ & - & - \\
\hline Active(\%) LAEF Ap2C & $19.66 \pm 14.7$ & - & - \\
\hline$E(\mathrm{~cm} / \mathrm{s})$ & $64.52 \pm 15.8$ & $89.93 \pm 16.3$ & \\
\hline$E / e^{\prime}$ & $8.15 \pm 3.57$ & $8.25 \pm 1.84$ & $0.627^{\Delta}$ \\
\hline E/A & $1.095 \pm 0.55$ & - & - \\
\hline$A^{\prime}(\mathrm{cm} / \mathrm{s})$ & $8.12 \pm 2.02$ & - & - \\
\hline
\end{tabular}

LV- left ventricular, TDD- telediastolic diameter, TSD- telesystolic diameter, LVEF-left ventricular ejection fraction,AP Diameter- antero posterior left atrial diameter, LAVI-left atrial volume indexed,Vmax- maximal left atrial volume, Vpre A- pre A left atrial volume, Vmin-mimim left atrial volume, LAEI-left atrial expansion index, LAEF-left atrial ejection fraction, Ap 4C-apical 4 chamber view, Ap 2C-apical 2 chamber view.

*Shapiro-Wilk Test, **Student T-Test, ***Levene's Test for Equality of Variances, ${ }^{\Delta}$ Mann-Whitney U Test

Table 1. Echocardiographic characteristics parameters in SR patients and in AF patients 


\section{INTERNAI}

\section{Original papers}

of those having mitral regurgitation $>$ II.

The strain of the 3 atrial functions did not vary according to the types of AF in any of the groups. In group A, the R\% as well as reservoir strain for each apical section was significantly higher compared to group B. $P<0.001$. The value of the $C D C \%$ was also significantly higher in patients in group $A$ versus those in group $\mathrm{B}:-9,01 \pm 4,56 \%$ respectively $-6,5 \pm$ 2,66\%; $P=0.029$ (Table 2).

It was found that the degree of left atrial dilation mainly influences the reservoir and pump functions, in which case the severe atrial dilation was associated with a significant decrease in atrial systolic function in both groups and with a significant decrease in atrial contractile capacity in those examined in SR. At the same time, the strain of each atrial function was significantly correlated with the corresponding volumetric function (Figure 5), a finding that is also valid for the R\% strain and the ability of left atrial relaxation expressed through LAEI in patients with AF.

With regards to the diastolic function, it was observed that the patients who had high values of the R\% had lower LVEDP - expressed through the $E / e^{\prime}$ ratio, a significant correlation for group in SR $(P=0.016 ; R=-0,430)$, but without reaching the statistical significance in the case of group $B(P=0.052, R=0,393)$. The low strain of the pump function was significantly and positively associated with low values of the transmitral E/A ratio
$(P<0.001 ; R=-0,430)$ and with low velocities of the a' wave $(P=0,014, R=-0,647)$.

\section{Discussion}

Studies have shown that the mechanics of left atrial deformation would be the most important in developing $\mathrm{AF}$, with a strong correlation between the low $\mathrm{R} \%$ function and that of the contractile one in the patients with paroxysmal AF existing, changes that precede LA dilation $^{(7)}$.

The left atrial systolic strain is considered a predictor of mortality, having the highest performance in predicting cardiovascular events compared to conventional parameters, and it can be observed that at a cut-off value $<19 \%$ the occurrence of new events such as stroke, AF, myocardial infarction, the necessity for coronary revascularization increses significantly ${ }^{(8)}$.

In the present study, we attempted to determine the values of the left atrial strain in patients with AF and to establish a parameter which could be a predictor for the maintaining of SR. Thus, according to the ROC curve, it was observed that the cut-off value of the reservoir strain $>13,25 \%$ has a Se of $90.9 \%$ and a Sp of $100 \%$ for the prediction of the maintaining of the RS (Figure 6), and when increasing with a unit of the $R(\%)$ function, the chance that $\mathrm{SR}$ is being maintained increases by 1,933 times ( $95 \% \mathrm{Cl}$ : 1,326-2,816). 


\begin{tabular}{|c|c|c|c|}
\hline \multicolumn{5}{|c|}{ Reservoir and conduit left atrial strain in SR patients and in AF patients } \\
\hline PARAMETERS & SR & AF & P value \\
\hline R\% & $20.2 \pm 6.225$ & $6.505 \pm 2.66$ & p $<0.001$ \\
\hline R\% Ap 4C & $20.793 \pm 7.28$ & $6.903 \pm 3.762$ & p $<0.001$ \\
\hline R\% Ap 2C & $20.872 \pm 7.42$ & $7.65 \pm 3.113$ & $p<0.001$ \\
\hline R\% Ap 3C & $18.96 \pm 6.004$ & $4.961 \pm 5.75$ & $p<0.001$ \\
\hline CDC\% & $-9.01 \pm 4.56$ & $-6.5 \pm 2.66$ & p \\
\hline CDC\% Ap 4C & $-10.25 \pm 5.414$ & $-6.903 \pm 3.762$ & p $<0.001$ \\
\hline CDC\% Ap 2C & $-8.95 \pm 5.443$ & $-7.65 \pm 3.113$ & 0.0520 \\
\hline CDC\% Ap 3C & $-7.851 \pm 4.848$ & $-4.961 \pm 5.75$ & 0.115 \\
\hline
\end{tabular}

$R \%$ - Mean reservoir strain, $R \%$ Ap $4 C$ - reservoir strain in apical 4 chamber view, $R \% A p 2 C$ reservoir strain in apical 2 chamber view, $R \%$ Ap 3C-reservoir strain in apical 3chamber view, CDC\%-Mean conduit strain, CDC\% Ap 4C-conduit strain in apical 4 chamber view, CDC\% Ap 2Cconduit strain in apical 2 chamber view, CDC\% Ap 3C-conduit strain in apical 3 chamber view

Table 2. Reservoir and conduit left atrial strain in SR patients and in AF patients

15

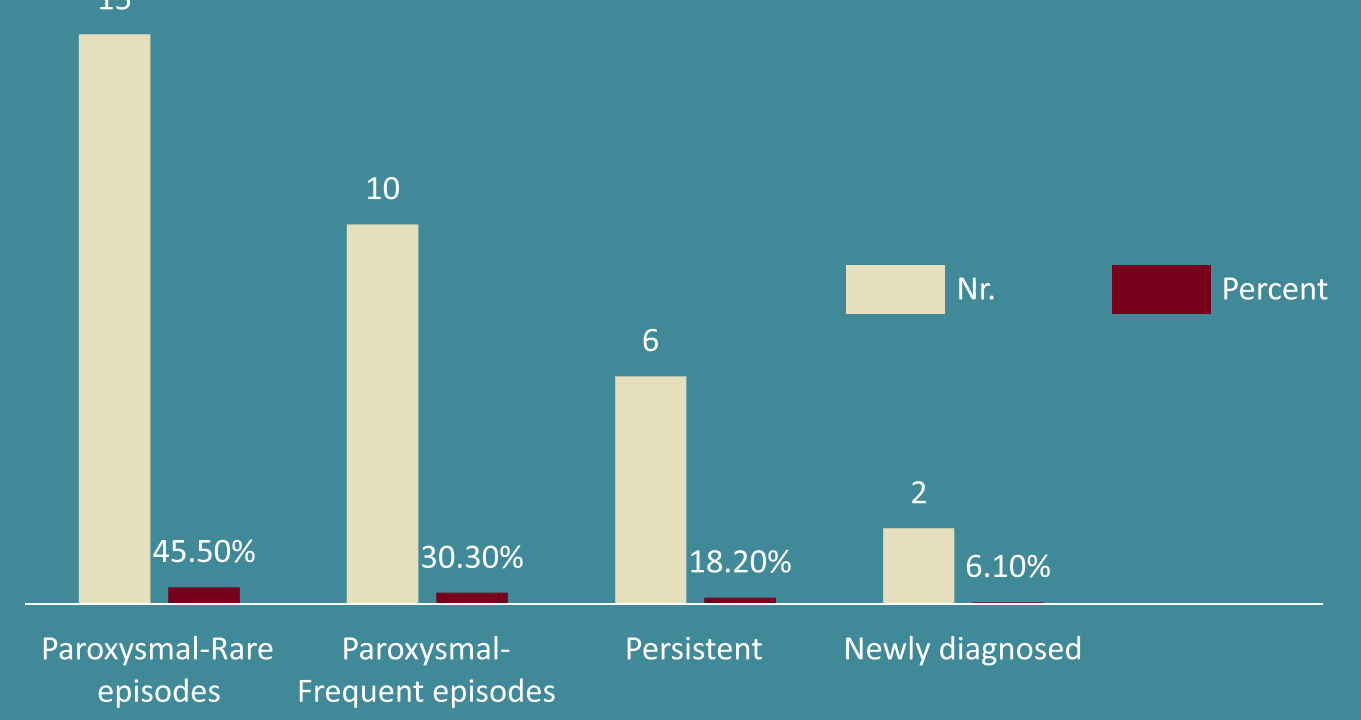

Figure 4. The distribution of patients examined in SR related to the type of AF 


\section{INTERNAL}

\section{Original papers}

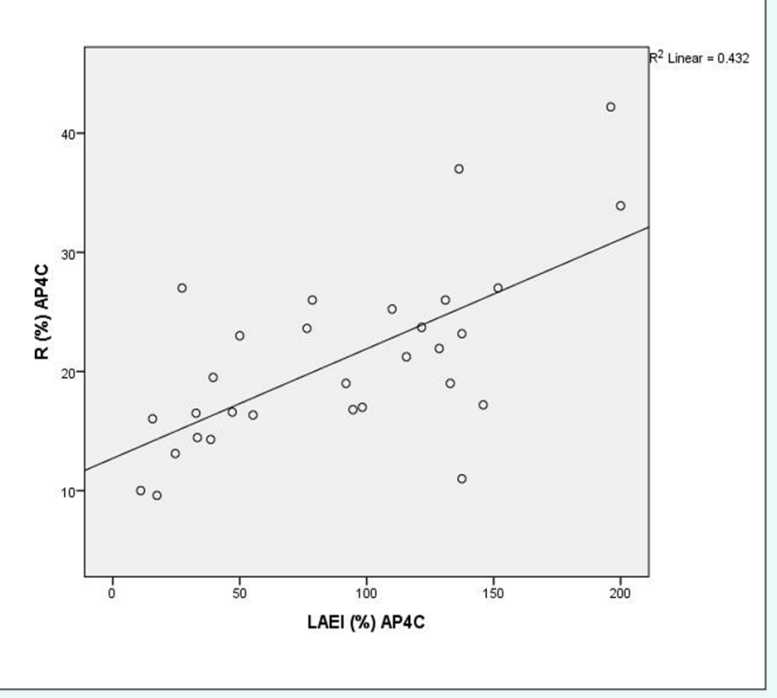

Figure 5. The correlation between left atrial strain reservoir function in Ap 4 C and LAEI(\%)

Our conclusion overlaps with the results from the literature, which also showed that $R \%$ would be the only variable that could differentiate patients who will maintain their RS, being a parameter dependent on both LA compliance and VS systolic function, in contrast with atrial volumes and $\mathrm{LAEI}^{(9)}$; the left atrial strain being a noninvasive marker of the degree of atrial fibrosis ${ }^{(7)}$.

The CDC\% could not predict the recurrence of $A F$ as it reflects the passive function of $\mathrm{LA}^{(9)}$.

Yoon et al. detected a cutt off value of systolic strain $<30,9 \%$ as a good predictor of the evolution of AF progression from paroxysmal to persistent, increasing the risk of arrhythmia progression to permanent 4 times (Hazard Ratio=4,224, $\mathrm{P}=0,01)^{(10)}$. At the same time, it has been shown that R\% can be a useful parameter in detecting paroxysmal episodes in patients with cryptogenic stroke and undilated $L^{(11)}$.

Motoki et al observed that in patients with a history of $A F, R \%$ is significantly lower in comparison to healthy subjects, revealing a value of $18,04 \pm 5,98 \%$ in the analysis of the strain through 2D STE ${ }^{(12)}$.

The systolic atrial strain correlates significantly with the degree of diastolic dysfunction, which is especially important in advanced stages, when the distinction between different degrees is difficult to make. It has been observed that a cutt off value of $19 \%$ of the peak systolic longitudinal strain may differentiate between grade II and grade III diastolic dysfunction. ${ }^{13}$ In our study, there was no significant correlation between the $\mathrm{R} \%$ and the $E / A$ ratio $(R=-0,338)$, but the patients with high $\mathrm{R} \%$ values significantly and negatively associated, in a moderate degree, higher values of the $E / e^{\prime}$ ratio ( $p$ $=0.016, \mathrm{R}=-0.430$ ).

There are studies that have tried to determine if the parameters of atrial deformation could be a feasible index of appreciation of LVEDP and it has been shown that especially in patients with preserved LVEF, the good correlation between the longitudinal global strain and the $E / e^{\prime}$ corresponded with the increased LVEDP measured by cardiac catheterization ${ }^{(14)}$. 
Older patients from group $A$ had a significantly lower value of left atrial systolic function: $P=0.012, R=-0,432$. The $R \%$ decrease with age corresponded to the results of the literature studies ${ }^{15}$, some also registering the increase of the pump SR necessary to maintain the ventricular filling ${ }^{(16)}$.

In our study, the systolic strain was not influenced by the anthropometric parameters, in contrast to the literature that detected its low values in patients with high BSA and high values in those with a high $\mathrm{BMI}^{(2)}$.

The patients examined in the AF had an $\mathrm{R} \%$ of $6,505 \pm 2,66 \%$. In a study that included 100 patients with AF, the 2D STE method found that the average atrial systolic peak was $10+ - \pm 4,0 \%{ }^{(17)}$.

\section{Conclusions}

In the present study the atrial strain of R\% and $C D C \%$ has significantly higher values in patients with a history of AF but examined in SR compared to subjects in AF. Of all the analyzed parameters that were associated between the 2 groups, it was found that only the atrial reservoir strain, as the only variable, has highest predictive power of maintaining SR.

Limitations: the small number of patients included in order to be able to identify based on the values of the strain the patients with prolonged duration and frequent recurrence of $A F$; the less precise demarcation of $R \%$ in 2D STE analysis in AF patients and the reproducibility of the measurements, not being able to make an analysis of the interobserver variability, there being no second independent observer.

\section{References}

1. Ginghina C. Mic tratat de cardiologie. Editura Academiei Romane: 2017;24:867-870.

2. Pathan F, D'Elia N, Nolan TM, et al. Normal ranges of left atrial strain by speckle-tracking echocardiography: A systematic review and meta-analysis. I Am Soc Echocardiogr. 2017;30:59-70.

3. Popescu BA, Ginghina C. Ecografia Doppler. Editura Medicala: 2011;5: 57-69.

4. Mochizuki A, Yuda S, Oi Y, et al. Assesment of left atrial deformation and synchrony by three-dimensional speckle tracking echocardiography: comparative studies in healthy subjects and patients with atrial fibrillation. J Am Soc Echocardiogr. 2013 Febr;26(2):16574.

5. Lang RM, Badano LP, Mor-Avi V, et al. Recommendations for cardiac chamber quantification by echocardiography in adults: An update from the American Society of Echocardiography and European Association of Cardiovascular Imaging. European Heart Journal-Cardiovascular Imaging. 2015;16,223-271.

6. Badano PL, Kolias TJ, Muraru D, et al. Standarzation of left atrial, right ventricular and right atrial deformation imaging using two-dimensional speckle tracking echocardiography: a consens document of the EACVI/ASE/Industry Task Force to standardize deformation imaging. European Heart JournalCardiovascular Imaging. 2018;19:591-600.

7. Yuda S, Muranaka A, Tetsufi M. Clinical implications of left atrial function assessed by speckle tracking echocardiography. Journal of Echocardiography.2016; 14(3):104-112.

8. Cameli M, Lissi M, Focardi M, et al. Left atrial deformation analysis by speckle tracking echocardiography for prediction of cardiovascular outcomes. Am J Cardiol 2012;110:264-269.

9. Di Salvo G, Caso P, Piccolo RL et al. Atrial myocardial deformation properties predict the maintenance of sinus rhytm after external cardioversion of recent onset lone atrial fibrillation- A color Doppler myocardial imaging and transthoracic and transesophageal echocardiographyc study. Circulation. 2005;112:387395.

10. Yonn YE, Youngoh I, Kim SA, Park KH, Kin SH, PacgJH. Echocardiographic predictors of progression to persistent or permanent atrial fibrillation in patients with paroxysmal atrial fibrillation. Journal of the American Society of Echocardiography. 2015; 28(6):709-717.

11. Pogola J, Gonzalez-Alujas T, Flores A, et al. Left atrial strain is a surrogate marker for detection of atrial fibrillation in cryptogenic strokes. Stroke. 2014 Aug;45(8):e164-6.

12. Motoki H, Dahiya A, Bhargava M, et al. Assessment of left atrial mechanics in patients with atrial fibrillation: 


\section{INTERNAL Original papers}

a comparison between 2D speckle based strain and velocity vector imaging. J Am Soc Echocardiogr. 2012;25(4):428-435.

13. Singh A, Addetia K, Maffessanti F, et al. LA strain for categorization of $L V$ diastolic dysfunction. JACC Cardiovasc Imaging. 2017Jul;10(7):735-743.

14. Cameli M, Sparla S, Losito M, et al. Correlation of left atrial strain and Doppler measurements with invazive measurement of left ventricular end-diastolic pressure in patients stratified for different values of ejection fraction. Echocardiography 2016;33:398-405).

15. Morris $A D$, Takeuchi $M$, Krisper $M$, et al. Normal values and clinical relevance of left atrial function analysed by speckle-tracking echocardiography: multicentre study. European Heart Journal Cardiovascular Imaging (2015) 16:364-372.

16. Vieira MJ, Teixeiria R, Goncalves $L$, et al. Left atrial mechanics: Echocardiographic assessment and clinical implications. J Am Soc Echocardiography. 2014;27:46368.

17. Leong DP, Penhall A, Perry R, et al. Speckle-tracking strain of the left atrium: a transoesophageal echocardiographic validation study. European Heart Journal- Cardiovascular Imaging (2013)14,898-905. 